\title{
Risk factors of fever after ALTA injection sclerotherapy for hemorrhoids
}

\author{
Yano $T^{*}$ \\ Yano Proctological Clinic, Kameicho, Takamatsushi, Kagawa 760-0050, Japan
}

\begin{abstract}
Aim: While fever is a well-known complication of Aluminum potassium sulfate and tannic acid (ALTA) injection sclerotherapy for hemorrhoids, risk factors for fever have not been studied to date. I therefore conducted this study to clarify the risk factors for fever following ALTA therapy.

Methods: Multivariate analysis was performed, only age, history of ALTA therapy and ALTA dosage showed significant differences.

Conclusion: We should inform patients of the high likelihood of developing fever following the therapy and prescribe draft of antipyretic analgesics.
\end{abstract}

\section{Introduction}

Aluminum potassium sulfate and tannic acid (ALTA) injection sclerotherapy for hemorrhoids is widely used in Japan due to its good outcomes and less invasiveness [1,2]. While fever is a well-known complication of ALTA therapy, risk factors for fever have not been studied to date. I therefore conducted this study to clarify the risk factors for fever following ALTA therapy.

\section{Methods}

\section{Patients}

This was a retrospective observational study of patients who underwent ALTA therapy for internal hemorrhoids between December 2012 and March 2018 at Yano Proctological Clinic in Takamatsu, Japan. Body temperatures were measured and recorded during examinations the day after ALTA therapy. Patients with a body temperature of $37.0^{\circ} \mathrm{C}$ or higher were considered to have fever and assigned to a "fever group," while patients with a body temperature of lower than $37.0^{\circ} \mathrm{C}$ were not considered to have fever and were assigned to a "non-fever group." After excluding 15 patients who did not attend examinations the day after ALTA therapy, a total of 954 patients were subject to analysis, of which 41 patients in the fever group and 913 in the non-fever group.

\section{Procedure}

After surgeon confirm fever free, ALTA therapy was administered by submucosally injecting an ALTA solution to treat lesional hemorrhoids by inserting a Z-type anoscope while the patients lay in the Sims' position under no anesthesia. The surgeon recorded the number of hemorrhoids treated and the dosage of ALTA solution $(\mathrm{mL})$ administered to each patient. After one hour of rest following completion of therapy, the patients were visually checked for any abnormalities using an anoscope and subsequently discharge to home.

\section{Statistical analysis}

The method of statistical analysis was a univariate analysis using fever as the objective variable converted into a binary nominal variable ("present" or "absent"), and sex, age, hemorrhoid grade (based on the Goligher classification), number of hemorrhoids, history of ALTA therapy, and ALTA dosage as the six explanatory variables. Only the items with a $\mathrm{P}$ value of less than 0.20 in the univariate analysis were subject to multivariate analysis where the items were forcibly entered into a logistic regression model. The statistical software SPSS was used for statistical processing and chi-square tests, Mann-Whitney U tests, Student's t-tests, and Wald tests were used to determine the existence of significant differences using a $\mathrm{P}$ value of 0.05 or less.

\section{Results}

The incidence of fever was $4.3 \%$. The median body temperature of the fever group $(\mathrm{n}=41)$ was $37.5^{\circ} \mathrm{C}$ (range: $37.0-39.4^{\circ} \mathrm{C}$ ) and all patients with a history of ALTA therapy were undergoing therapy for the second time.

The results of the univariate analysis of sex, age, Goligher classification, number of hemorrhoids, history of ALTA therapy, and ALTA dosage are presented in Table 1. Of the four items entered in to the multivariate analysis (age, Goligher classification, history of ALTA therapy and ALTA dosage), only age, history of ALTA therapy and ALTA dosage showed significant differences. The results are presented in Table 2.

\section{Discussion}

ALTA therapy has a strong therapeutic effect, which will be used widely in other countries just as well as Japan. The fact that this study revealed findings related to complications is significant. Three risk factors for fever, age, history of ALTA therapy, and ALTA dosage were identified. This means that young patients, patients undergoing ALTA therapy for a second time, or patients receiving a large ALTA dosage

${ }^{\star}$ Correspondence to: Takaaki Yano, MD, 11-7 Kameicho, Takamatsushi, Kagawa 760-0050 Japan, E-mail: yanotakaaki@hotmail.co.jp

Received: December 27, 2018; Accepted: January 21, 2019; Published: January 23,2019 
Table 1. Results of the univariate analysis

\begin{tabular}{|l|c|c|c|}
\hline & $\begin{array}{c}\text { Fever group } \\
(\mathbf{n}=\mathbf{4 1})\end{array}$ & $\begin{array}{c}\text { Non-fever group } \\
(\mathbf{n = 9 1 3})\end{array}$ & $\boldsymbol{P}$-value \\
\hline Sex & $28 / 13$ & $539 / 374$ & 0.24 \\
Male/Female & $51.2 \pm 14.7$ & $60.3 \pm 17.2$ & $<0.01$ \\
\hline Age (mean \pm SD) & 0 & 24 & \\
\hline Hemorrhoid grade & 3 & 203 & 0.054 \\
$\quad$ Grade I & 38 & 686 & \\
Grade II & & & \\
Grade III & 11 & 268 & 0.61 \\
\hline Number of hemorrhoids & 20 & 451 & \\
1 & 10 & 194 & $<0.01$ \\
2 & $13 / 28$ & $58 / 855$ & 0.15 \\
\hline 3 & $13.5 \pm 5.3$ & $12.3 \pm 4.3$ & \\
\hline ALTA history & & & \\
Yes/No & & & \\
\hline ALTA dosage $(\mathrm{mL})$ & & & \\
\hline
\end{tabular}

Table 2. Results of the multivariate analysis

\begin{tabular}{|c|c|c|c|}
\hline & Odds ratio & $\begin{array}{c}\mathbf{9 5 \%} \text { confidence } \\
\text { interval }\end{array}$ & $\boldsymbol{P}$-value \\
\hline Age & 0.97 & $0.95-0.99$ & $<0.01$ \\
\hline Hemorrhoid grade & 2.49 & $0.78-7.97$ & 0.12 \\
\hline ALTA history & 7.59 & $3.45-16.7$ & $<0.01$ \\
\hline ALTA dosage & 1.08 & $1.00-1.16$ & 0.038 \\
\hline
\end{tabular}

are susceptible to developing fever. However, no feasible preventive measures exist for physicians to employ against these three factors prior to therapy. We should inform patients of the high likelihood of developing fever following the therapy and prescribe draft of antipyretic analgesics.

Two issues should be noted in regard to the results of this study. These are the incidence of fever and the severity of fever. The incidence has previously been reported, at $2 \%-9 \%[1,3]$, which is not much different from the $4.3 \%$ found in the present study and reconfirms fever as a comparatively rare complication. As for the severity of fever, we saw cases of fever as high as $39.4^{\circ} \mathrm{C}$, which means that clinicians should be aware prior to therapy of the possibility of patients developing a high fever.

To date, no papers have discussed the mechanism behind fever following ALTA therapy. We speculate that complications arise from the difficulty that young patients have resting after therapy and the progressive increases in total dosages injected. In addition to it, the incidence has previously been reported, at $2 \%-9 \%[1,3]$, which is not much different from the $4.3 \%$ found in the present study and reconfirms fever as a comparatively rare complication.

Finally, we must mention the limitations and issues associated with this study. This was a retrospective study. We cannot discuss any fever that developed subsequent to the day after therapy. The significant risk factors for fever following ALTA therapy that were found in this study appear to be of great interest and strong significance.

\section{Conflicts of interest}

The author declares no conflicts of interest.

\section{References}

1. Takano M, Iwadare J, Ohba H, Takamura H, Masuda Y, et al. (2006) Sclerosing therapy of internal hemorrhoids with a novel sclerosing agent. Int J Colorectal Dis 21: 44-51. [Crossref]

2. Miyamoto H, Asanoma M, Miyamoto H, Shimada M (2012) ALTA injection sclerosing therapy:non-excisional treatment of internal hemorrhoids. Hepatogastroenterolog 59: 77-80. [Crossref]

3. Hachiro Y, Kunimoto M, Abe T, Kitada M, Ebisawa Y (2011) Aluminum potassium sulfate and tannic acid (ALTA) injection as the mainstay of treatment for internal hemorrhoids. Surg Today 41: 806-809. [Crossref] 